\title{
Antimicrobial effect of dried sage on the microbiological state of fresh Hungarian sausage
}

\author{
Miklós Posgay - Viktória Kapcsándi - Erika Hanczné Lakatos \\ Department of Food Science, Faculty of Agricultural and Food Sciences, Széchenyi István University \\ posgay.miklos@sze.hu
}

\begin{abstract}
SUMMARY
The purpose of this study was to evaluate the microbial effect of dried sage (Salvia officinalis L.) on the traditional Hungarian sausage. We added $0.5,1,1.5$, and $2 \mathrm{w} / \mathrm{w} \%$ of sage to the sausages and tested them on the $0^{\text {th }}, 7^{\text {th }}$ and $14^{\text {th }}$ day. The added dried sage had no effect on the tested microorganisms, but the sage extract inhibited Salmonella, Enterococcus faecium and Staphylococcus aureus.
\end{abstract}

Keywords: sausage; sage; antimicrobial effect

\section{INTRODUCTION}

Throughout human history, sage has been a wellknown herb; it was used by the Chinese to develop drugs, or by the Egyptians, Greeks and Romans as a herb and drug. Salvia officinalis was one of the species which has pharmacological effects. The plant has biological activities, for example virustatic, fungistatic, and antibacterial effects. The biological effects of sage depend on the content of camphor, 1,8-cineole, $\alpha$ thujone, and $\beta$-thujone. (Hamidpour et al., 2014) Sage has antibacterial activity through 1,8-cineole, camphor, thujone against Bacillus subtilis, Bacillus cereus. Two other sage components, oleanolic acid and ursolic acid, can also inhibit different pathogenic bacteria such as penicillin-resistant Streptococcus pneumonia, and methicillin-resistant Staphylococcus aureus. Shirazi et al. (2008) tested in vitro the antibacterial effect of sage extract against Salmonella typhi, Salmonella flexneri, Salmonella sonnei, Pseudomonas vulgaris, Staphylococcus aureus, enterotoxigenic Escherichia coli (ETEC), and Pseudomonas aeruginosa. They found that sage extract had no effect on $P$. aeroginosa, and ETEC, but it inhibited P. vulgaris, S. flexneri, and $S$. sonnei. Moreover, it had as strong effect as ampicillin and streptomycin against $S$. typhi. The effect against $S$. aureus was as strong as a wide scale of antibiotics used against $S$. aureus such as vancomycin (Shirazi et al., 2008; Ghorbani and Esmaeilizadeh, 2017). The active components of plants are usually hydrophobic by nature. Because of this attribution their primary target is the cell membrane. They can cause loss of ions, enzymes and metabolites from the cell which will lead to the death of the cell (Mitić-Ćulafić et al., 2005).

Císarová et al. (2018) tested $\alpha$-thujone and $\beta$ thujone, 1,8-cineole, borneol, sage extract, and sage essential oil with E. coli, K. pneumoniae, E. faecalis, and $S$. aureus. They found $\alpha$-thujone and $\beta$-thujone could not inhibit these strains. E. faecalis was resistant to the sage essential oil, while 1-8-cineol had no effect on $E$. coli and $S$. aureus. The sage extract had a strong antibacterial effect in case of $E$. faecalis and $K$. pneumoniae (Císarová et al., 2018).
There are sprays with added herbal active ingredient used by the food industry. They have several advantages, like easy handling, short contact with the medium, good reproducibility. These sprays can only be used on the surface of the product. Maybe an extract used in the product could have more advantages, for example it has a positive effect on the taste of the product, and the appearance of the product. The food industry is on the development of healthier products in the past years, one of the additive group is the synthetic antioxidants. They delay or inhibit for example oxidation in foods. The main point is the usage of plants and their active components, which are of natural origin (Pavlić et al., 2017; Munekata et al., 2020).

One of the most common meat products is the fresh pork sausage, which has several types depending on the country or region of origin, the applied spices and herbs. Fresh pork sausages have high water activity, they are not heat treated until the consumption so the basic microbial flora of fresh meat has effect on the shelf life of the product. The food industry is trying to replace the artificial preservatives with agents of natural origin. Natural agents have disadvantages, they have higher price than artificial preservatives and they are not as effective as the artificial ones (Šojić et al., 2018).

\section{MATERIALS AND METHODS}

The minced pork meat was obtained from a local meat product factory, Darnó-hús (Funkcio Ltd, Darnózseli, Hungary), the used spices were obtained from commercial market (Kotányi Hungary Spices Processing and Sales Ltd., Törökbálint, Hungary; Lacikonyha Hungary Ltd., Budapest, Hungary). The used dried and ground sage was harvested from the parcel of the Széchenyi István University, Faculty of Agricultural and Food Sciences, Department of Food Science.

\section{Preparation of the pork sausage}

The raw pork meat was purchased in a ground form. We added the needed spices according to the recipe of the traditional Hungarian sausage: sweet paprika 
powder $(1.88 \mathrm{w} / \mathrm{w} \%)$, salt $(1.88 \mathrm{w} / \mathrm{w} \%)$, black pepper $(0.38 \mathrm{w} / \mathrm{w} \%)$, white pepper $(0.19 \mathrm{w} / \mathrm{w} \%)$, cumin powder $(0.38 \mathrm{w} / \mathrm{w} \%)$, nutmeg powder $(0,09 \mathrm{w} / \mathrm{w} \%)$, and freshly ground garlic $(1.40 \mathrm{w} / \mathrm{w} \%)$, then we mixed it and 1-1 kilograms were measured into plastic boxes. We added $0.5,1.0,1.5$ and $2.0 \mathrm{w} / \mathrm{w} \%$ of sage to the pulp and mixed them. One of the batter did not contain sage powder, that was the control. The batters were stuffed into natural casing (pig small intestines, Böllérbolt, Pécs, Hungary) and then were vacuum packed into 150x200 vacuum bags (Gasztronauta Ltd., Győr, Hungary). The core temperature of the meat and the pulp did not reach $5{ }^{\circ} \mathrm{C}$. We kept the sausages at $4{ }^{\circ} \mathrm{C}$ until we performed the tests. The chilled products were tested without heat treatment.

\section{Extraction of the sage}

We extracted the sage according to Durling et al. (2007). We ground (Hausmeister Ltd., Norfolk, United Kingdom) the sage that was previously dried in a drying oven for $24 \mathrm{~h}$ on $35^{\circ} \mathrm{C}$. We prepared the extraction solution by using $99.8 \%$ ethanol and deionised water. The solution contained $81 \%$ ethanol, the solvent-tosage ratio was $6: 1$. We kept the extraction at $40{ }^{\circ} \mathrm{C}$ for $4 \mathrm{~h}$. To remove the ethanol from the solution we used drying oven for $3 \mathrm{~h}$ at $70^{\circ} \mathrm{C}$, the leftover solution was poured into vials and kept under $4{ }^{\circ} \mathrm{C}$ until the tests were evaluated.

\section{Microbiology analysis}

The sausages were tested on the $0^{\text {th }}, 7^{\text {th }}$ and $14^{\text {th }}$ days. The samples were tested for Staphylococcus aureus on Baird Parker (BP, Biolab Ltd, Budapest, Hungary) agar at $37^{\circ} \mathrm{C}, 48 \mathrm{~h}$, for yeast and mold on Yeast Glucose Chloramphenicol (YGC, Biolab Ltd, Budapest, Hungary) agar at $25{ }^{\circ} \mathrm{C}, 120 \mathrm{~h}$, for Clostridium perfringens on Tryptose Sulfite Cycloserine (TSC, Biolab Ltd, Budapest, Hungary) agar at $37{ }^{\circ} \mathrm{C}, 48 \mathrm{~h}$, coliforms and Eschericia coli on ChromoCult Coliform (CC, Biolab Ltd, Budapest, Hungary) agar at $37^{\circ} \mathrm{C}, 48 \mathrm{~h}$, and total plate count on Plate Count (PC, Biolab Ltd, Budapest, Hungary) agar at $30{ }^{\circ} \mathrm{C}, 72 \mathrm{~h}$. In case of Salmonella the sample was first enriched in Buffered Pepton Water (Biolab Ltd, Budapest, Hungary), then selectively enriched in Rappaport-Vasiliadis broth (RV, Biolab Ltd, Budapest, Hungary), and finally one more selective enrichment was done on Xylose Lysine Desoxychoate agar (XLD, Biolab Ltd, Budapest, Hungary).

\section{Agar well diffusion test}

The extracted sage solution was tested for inhibition for Salmonella, E. coli, S. aureus, and E. faecium on Tryptic Soy Agar (Biolab Ltd, Budapest, Hungary) at $37{ }^{\circ} \mathrm{C}$ for $24 \mathrm{~h}$. After the incubation time we measured the inhibition zones around the drilled holes.

\section{RESULTS AND DISCUSSION}

We tested the sausages on the $0^{\text {th }}, 7^{\text {th }}$ and $14^{\text {th }}$ days. Vacuum packed sausages do not have a longer shelf life than 14 days because of the microbiological and enzyme activity.

On the first and last test round, we did not find typical $C$. perfringens colonies on the surface of the agar. On the $7^{\text {th }}$ day in case of $0 \%$ of sage $1.1 * 10^{3}$, in case of $0.5 \% 1.1 * 10^{3}$ and in case of $1 \%$ of sage $6.8 * 10^{2}$ $\mathrm{CFU} / \mathrm{g}$ were detected in the experimental groups, respectively. According to the Decree No. 4 of 1998 of the Ministry of Health the limit for $C$. perfringens is $10^{2}$ $\mathrm{CFU} / \mathrm{g}$, consequently, on the $7^{\text {th }}$ day sausages it reached and exceeded the limit.

In the case of $S$. aureus we found black colonies on the BP agar, but they did not have the typical clear zone around the colonies which characterize the typical $S$. aureus colonies on BP agar caused by the egg yolk tellurite emulsion (Biolab Ltd, Budapest, Hungary). The confirmatory test was evaluated by Staphytect Plus (Thermo Fisher Scientific Inc, Waltham, USA), but we did not detect agglutination.

In the test of $E$. coli the colonies showed an increase until the $7^{\text {th }}$ day, and then a decrease was observed on the $14^{\text {th }}$ day (Table 1). The Decree No. 4 of 1998 of the Ministry of Health does not regulate the limit of $E$. coli in fresh sausages.

Table 1. Microbial results of the Escherichia coli test (CFU/g)

\begin{tabular}{cccccc}
\hline days & \multicolumn{5}{c}{ Percentage of sage } \\
\hline & \multicolumn{1}{c}{0} & 0.5 & 1 & 1.5 & 2 \\
0 & $2.9^{*} 10^{1}$ & $3.8 * 10^{1}$ & $5.8^{*} 10^{1}$ & $7,1^{*} 10^{1}$ & $5.4^{*} 10^{1}$ \\
7 & $5^{*} 10^{1}$ & $1.3 * 10^{2}$ & $4.4^{*} 10^{2}$ & $8.8^{*} 10^{1}$ & $6.2 * 10^{2}$ \\
14 & $1.7^{*} 10^{1}$ & $8.3 * 10^{1}$ & $1.3^{*} 10^{2}$ & $0.8 * 10^{1}$ & $1.2^{*} 10^{2}$ \\
\hline
\end{tabular}

In the case of coliforms nearly ten times more CFU/g were found compared to the E. coli tests (Table 2 ). The number of coliforms increased until the $7^{\text {th }}$ day as well, whereas on the last day the number nearly approached the initial values of day 0 . The Decree No. 4 of 1998 of the Ministry of Health does not regulate the limit of coliforms in meat products. 
Table 2. Microbial results of coliforms (CFU/g)

\begin{tabular}{cccccc}
\hline days & \multicolumn{5}{c}{ Percentage of sage (\%) } \\
\hline & 0 & 0.5 & 1 & 1.5 & 2 \\
0 & $5.1 * 10^{2}$ & $4.8 * 10^{2}$ & $4.5 * 10^{2}$ & $4.1 * 10^{2}$ & $3.6 * 10^{2}$ \\
7 & $3.7 * 10^{3}$ & $2.5 * 10^{3}$ & $8.4 * 10^{3}$ & $1.2 * 10^{4}$ & $8.6 * 10^{3}$ \\
14 & $4.3 * 10^{2}$ & $5.7 * 10^{2}$ & $6.2 * 10^{2}$ & $6.5 * 10^{2}$ & $5.9 * 10^{2}$ \\
\hline
\end{tabular}

In the case of yeast the sausage which did not contain sage had less than $10 \mathrm{CFU} / \mathrm{g}$ of yeast colonies (Table 3). Colonies showed rising only on the $7^{\text {th }}$ day. Sausages that contained sage had a $10^{2}$ initial yeast number but they reached less than 10 on the $14^{\text {th }}$ day. Only the $2 \%$ sage product had increasing numbers until the $7^{\text {th }}$ day, but it reached less than 10 on the $14^{\text {th }}$ day, as well. We could not find yeast colonies on the agar plates.

In the case of mold their number showed a halving in case of the $7^{\text {th }}$ day test (Table 4). On the $14^{\text {th }}$ day we could not find typical colonies on the agar plates. We also tested the sage, it had $4.5^{*} 10^{2}$ initial yeast number.

Table 3. Microbial results of the yeast test (CFU/g)

\begin{tabular}{cccccc}
\hline days & \multicolumn{5}{c}{ Percentage of sage $(\%)$} \\
\hline & 0 & 0.5 & 1 & 1.5 & 2 \\
0 & $<10^{1}$ & $4.05^{*} 10^{2}$ & $4.1^{*} 10^{2}$ & $3.3^{*} 10^{2}$ & $5.7 * 10^{2}$ \\
7 & $3.1^{*} 10^{2}$ & $2.6^{*} 10^{2}$ & $1.5^{*} 10^{2}$ & $2.5^{*} 10^{2}$ & $7 * 10^{2}$ \\
14 & $<10^{1}$ & $<10^{1}$ & $<10^{1}$ & $<10^{1}$ & $<10^{1}$ \\
& & & & & \\
\hline
\end{tabular}

Table 4. Microbial results of mold test (CFU/g)

\begin{tabular}{cccccc}
\hline days & \multicolumn{5}{c}{ Percentage of sage (\%) } \\
\hline & 0 & 0.5 & 1 & 1.5 & 2 \\
0 & $5.6 * 10^{2}$ & $2.8^{*} 10^{2}$ & $2.3 * 10^{2}$ & $2.4 * 10^{2}$ & $4.5^{*} 10^{2}$ \\
7 & $2.4^{*} 10^{2}$ & $1.5^{*} 10^{2}$ & $1.3 * 10^{2}$ & $1.6 * 10^{2}$ & $1.5^{*} 10^{2}$ \\
14 & $<10^{1}$ & $<10^{1}$ & $<10^{1}$ & $<10^{1}$ & $<10^{1}$ \\
\hline
\end{tabular}

In the case of the total plate count we did not find the same results like in the case of other tested microorganisms (Table 5). We found only increasing, in three cases, the sausages which contained $1 \%, 0.5 \%$, and $1.5 \%$ on the $14^{\text {th }}$ day had decreasing. The logical result would be a decrease in the case of $2 \%$ of sage because it contained the most sage, it had the highest active component content but we found the highest increase in the case of $2 \%$. We tested the raw meat too, it contained $1.7 * 10^{5}$ microorganisms on the $0^{\text {th }}$ day. The increase was three and in one case four order of magnitude. Without the vacuum packaging these number could have been reached within few days and not in two weeks.

Table 5. Microbial results of total plate count test (CFU/g)

\begin{tabular}{cccccc}
\hline & days & & \multicolumn{3}{c}{ Percentage of sage (\%) } \\
\hline & 0 & 0.5 & 1 & 1.5 & 2 \\
0 & $2.9 * 10^{3}$ & $2.4 * 10^{3}$ & $2.4^{*} 10^{3}$ & $1.9 * 10^{3}$ & $1.4^{*} 10^{3}$ \\
7 & $3.6 * 10^{6}$ & $3.01 * 10^{6}$ & $5 * 10^{6}$ & $4.6^{*} 10^{6}$ & $3.9 * 10^{6}$ \\
14 & $7.3 * 10^{6}$ & $2.2 * 10^{6}$ & $9.3 * 10^{5}$ & $2.7 * 10^{6}$ & $1.54 * 10^{7}$ \\
\hline
\end{tabular}

\section{Agar well diffusion test}

Our sage extract did not have inhibitory effect on $E$. coli, the solution diffunded into the agar but we did not observe clear inhibition. The solution had inhibition for E. faecium, $S$. aureus and Salmonella. In case of $E$. faecium the average diameter was $7.7 \mathrm{~mm}$. The effect of the extract on $S$. aureus resulted in the clearest inhibition, in the average diameter of $10 \mathrm{~mm}$. The strongest inhibition was in the case of Salmonella, the average diameter was $20.3 \mathrm{~mm}$. 


\section{CONCLUSIONS}

The application of herb extracts is a new but rapidly developing trend in the food industry. The fresh or dry parts of herbs do not contain as much active components such as extracts like essential oils. The difference of the effects is clearly visible from the articles which tested the effects of essential oils against dried herbs. Dried herbs are needed because consumers are buying food products "with their eyes", too, therefore a product containing only essential oil will not have the same effect on the consumer like a product with essential oil and herb pieces.

The next studies will be about the essential oils and their effects on the microbial state and organoleptic properties of Hungarian fresh and riped sausages.

\section{ACKNOWLEDGEMENTS}

Supported by the ÚNKP-20-3-I, New National Excellence Program of the Ministry for Innovation and Technology from the source of the National Research, Development and Innovation Fund.

This work was supported by grant number EFOP3.6.3-VEKOP-16-2017-00008 entitled "Innovative Scientific Institutions in Domestic Agricultural Higher Education". The project is co-financed by the European Union and the European Social Fund.

\section{REFERENCES}

Císarová, M.-Ürgeová, E.-Hleba, L.-Charousová, I.-Božik, M.Klouček, P.-Maliar, T. (2018): Inhibition effects of some antimicrobial agents from Salvia officinalis L. on the growth of selected Gram-negative and Gram-positive bacterial strains, Journal of Microbiology, Biotechnology and Food Sciences, 8(3): 960-964.

Ghorbani, A.-Esmaeilizadeh, M. (2017): Pharmacological properties of Salvia officinalis and its components, Journal of Traditional and Complementary Medicine, 7,(4): , 433-440.

Hamidpour, M.-Hamidpour, R.-Hamidpour, S.-Shahlari, M. (2014): Chemistry, pharmacology, and medicinal property of sage (Salvia) to prevent and cure illnesses such as obesity, diabetes, depression, dementia, lupus, autism, heart disease and cancer, Journal of Traditional and Complementary Medicine, 82-88.

Mitić-Ćulafić, D.-Vuković-Gačić, B.S.-Knežević-Vukčević, J.Stanković, S. (2005): Comparative study on the antibacerial activity of volatiles from sage (Salvia officinalis L.), Archives of Biological Sciences, 57.
Munekata, P.E.S.-Rocchett, G.-Pateiro, M.-Lucini, L.-Domínguez, R.-Lorenzo, J.M. (2020): Addition of plant extracts to meat and meat products to extend shelf-life and health-promoting attributes: an overview, Current Opinion in Food Science, 31, 81-87.

Pavlić, B.-Teslić, N.-Vidaković, A.-Vidović, S.-Velićanski, A.Versari, A.-Radosavljević, R.-Zeković Z. (2017.): Sage processing from by-product to high quality powder: I. Bioactive potential, Induatrial Crops and Products, 107, 81-89.

Shirazi, M.H.-Ranjbar, R.-Eshraghi, S.-Amin, G.-Seyed Nouri, M.Bazzaz, N. (2008.): Inhibitory effects of Sage extract on the growth of enteric bacteria, Pakistan Journal of Biological Sciences, 487-489.

Šojić, B.-Pavlić, B.-Zeković, Z.-Tomović, V.-Ikonić, P.-KocićTanackov, S.-Džinić, N. (2018.): The effect of essential oil and extract from sage (Salvia officinalis L.) herbal dust (food industry by-product) on the oxidative and microbiogical stability of fresh pork sausages, LWT - Food Science and Technology, 89, 749-755. 